\title{
Achievement of Remission Endpoints with Secukinumab Over 3 Years in Active Ankylosing Spondylitis: Pooled Analysis of Two Phase 3 Studies
}

\author{
Xenofon Baraliakos - Filip Van den Bosch - Pedro M. Machado • \\ Lianne S. Gensler - Helena Marzo-Ortega • Bintu Sherif • \\ Erhard Quebe-Fehling • Brian Porter • Corine Gaillez • \\ Atul Deodhar
}

Received: October 29, 2020 / Accepted: December 5, 2020 / Published online: December 22, 2020

(C) The Author(s) 2020

\section{ABSTRACT}

Introduction: Clinical remission in patients with ankylosing spondylitis (AS) has been determined using composite indices such as the AS Disease Activity Score inactive disease (ASDAS-ID), Assessment of SpondyloArthritis

Supplementary Information The online version contains supplementary material available at https:// doi.org/10.1007/s40744-020-00269-6.

\section{Baraliakos $(\varangle)$}

Rheumazentrum Ruhrgebiet Herne, Ruhr-

University Bochum, Bochum, Germany

e-mail: xenofon.baraliakos@elisabethgruppe.de

F. Van den Bosch

Department of Internal Medicine and Pediatrics,

Ghent University, Ghent, Belgium

F. Van den Bosch

VIB Center for Inflammation Research, Ghent,

Belgium

P. M. Machado

Department of Rheumatology, University College London Hospitals NHS Foundation Trust, London, UK

P. M. Machado

Department of Rheumatology, Northwick Park

Hospital, London North West University Healthcare

NHS Trust, London, UK

P. M. Machado

Centre for Rheumatology and Department of

Neuromuscular Diseases, University College

London, London, UK international Society criteria partial remission (ASAS-PR), and low Bath AS Disease Activity Index (BASDAI) scores. The objective of this exploratory analysis was to evaluate the proportion of secukinumab-treated patients with AS achieving remission defined based on the ASDAS-ID (score $<1.3$ ), ASAS-PR or BASDAI score $\leq 2$.

Methods: The analysis pooled data from the MEASURE 1 and 2 studies over 3 years. The

\section{S. Gensler}

Department of Medicine/Rheumatology, University of California, San Francisco, San Francisco, CA, USA

\section{H. Marzo-Ortega}

NIHR Leeds Biomedical Research Centre, Leeds Teaching Hospitals Trust, Leeds Institute of Rheumatic and Musculoskeletal Medicine, University of Leeds, Leeds, UK

B. Sherif RTI Health Solutions, Research Triangle Park, NC, USA

E. Quebe-Fehling · C. Gaillez

Novartis Pharma AG, Basel, Switzerland

B. Porter

Novartis Pharmaceuticals Corporation, East

Hanover, NJ, USA

\section{A. Deodhar} Oregon Health and Science University, Portland, OR, USA 
proportion of patients who achieved ASDAS-ID, ASAS-PR, or BASDAI $\leq 2$ with secukinumab was compared with placebo at week 16; results for secukinumab-treated patients were summarized through week 156 . Sustainability of each criterion was assessed from week 16 to 156 using shift analysis. The association between each of these criteria and specific patient-reported outcomes (PROs), such as health-related quality of life, function, fatigue, and work impairment, was also explored.

Results: At week 16, a higher proportion of secukinumab-treated patients versus placebo achieved ASDAS-ID (17.6 vs. 3.5\%), ASAS-PR (15.4 vs. $4.1 \%)$, or BASDAI $\leq 2$ (22.3 vs. $6.4 \%)$ criteria (all $P<0.0001$ ), which were sustained through 156 weeks. Shift analysis showed that the majority of secukinumab-treated patients achieving remission at week 16 maintained their status at week 156 (ASDAS-ID, 57.1\%; ASAS-PR, $68.0 \%$ and BASDAI $\leq 2, \quad 74.3 \%)$. Remission was also associated with improved PROs over 156 weeks.

Conclusions: Secukinumab-treated patients maintained ASDAS-ID, ASAS-PR, or BASDAI $\leq 2$ from week 16 up to 3 years. Patients who achieved at least one of the three responses/ states, reported improvement in PROs, which suggests an association of clinical remission/ID with PROs in patients with active AS.

Trial registration: ClinicalTrials.gov: NCT01358175, NCT01863732, and NCT01649375

Keywords: Ankylosing spondylitis; Axial spondyloarthritis; Biologics; Interleukin-17; Low disease activity; Patient-reported outcomes; Remission; Secukinumab

\section{Key Summary Points}

\section{Why carry out this study?}

There is a lack of both evidence from randomized controlled trials and universally accepted remission criteria for axial spondyloarthritis, which are major barriers to the implementation of a treatment-to-target approach.
This study was performed to explore achievement of remission criteria defined as the Ankylosing Spondylitis (AS) Disease Activity Score inactive disease (ASDAS-ID), Assessment of SpondyloArthritis international Society criteria for partial remission (ASAS-PR), and low Bath AS Disease Activity Index (BASDAI) $\leq 2$ with secukinumab using pooled data from two phase 3 studies in patients with AS.

This is the first time that achievement of ASDAS-ID (score $<1.3$ ), ASAS-PR, and BASDAI $\leq 2$, which are reported in the same data set of patients with AS from the pivotal secukinumab MEASURE 1 and 2 studies.

\section{What was learned from the study?}

In this pooled analysis, the majority of secukinumab-treated patients who achieved low disease activity or inactive disease related to either the criteria of ASDAS, ASAS-PR, or BASDAI $\leq 2$ at week 16 maintained their status up to week 156 at an individual level.

These findings suggest that in addition to ASDAS-ID and ASAS-PR, BASDAI $\leq 2$ may be considered a useful disease activity cutoff as a pragmatic tool to assess remission in clinical practice in patients with AS.

\section{DIGITAL FEATURES}

This article is published with digital features, including a summary slide, to facilitate understanding of the article. To view digital features for this article go to https://doi.org/10.6084/ m9.figshare.13326197.

\section{INTRODUCTION}

Ankylosing spondylitis (AS) is a debilitating form of arthritis that primarily affects the axial skeleton. It is associated with impaired physical 
function, reduced work productivity, and health-related quality of life (HRQoL) [1-3]. The main goal of AS treatment is to control disease activity, with an emphasis on improvement of signs and symptoms and normalization of physical function and QoL [4]. Achievement of remission, inactive disease (ID), or low disease activity (LDA) is important in patients with axial spondyloarthritis (axSpA), including AS, since persistent high disease activity is associated with worse outcomes, including structural damage and spinal radiographic disease progression $[5,6]$. An international task force recommended that a treat-to-target (T2T) strategy should be the standard treatment approach in axSpA, with clinical remission, ID, or LDA as the desired response or target for physicians and patients [4]. However, the lack of evidence from randomized controlled trials (RCTs) and of universally accepted remission criteria are major barriers to the implementation of a T2T approach in axSpA [7-9].

Tumor necrosis factor inhibitors (TNFi) have been shown to be beneficial for the management of AS [10-12]. In clinical studies, up to $40 \%$ of patients with AS treated with TNFi were shown to achieve and sustain remission (AS Disease Activity Score for inactive disease [ASDAS-ID] $<1.3$ ), and $60 \%$ of patients (completers) were shown to achieve Bath AS Disease Activity Index (BASDAI) score $<3$ for up to 8 years [13, 14]. However, it has been shown that $20-40 \%$ of patients treated with TNFi experience an inadequate response (IR) or become intolerant to these therapies over time $[15,16]$.

Secukinumab, a human monoclonal

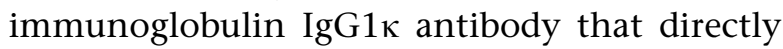
inhibits interleukin-17A, has been shown to provide rapid and sustained improvement in the signs and symptoms of active AS in pivotal phase 3 studies (MEASURE 1 and 2) [17-22]. Given the paucity of data on achievement of remission targets in the literature, the objective of this post hoc exploratory analysis was to evaluate the proportion of secukinumab-treated patients with AS who achieved remission criteria defined as ASDAS-ID, Assessment of SpondyloArthritis international Society partial remission (ASAS-PR), or BASDAI $\leq 2$ (a non- validated cutoff), using pooled data from the MEASURE 1 and 2 studies, over 3 years. The association between ASDAS-ID, ASAS-PR, and BASDAI $\leq 2$ and patient-reported outcomes (PROs) related to HRQoL, social functioning, work productivity, and activity impairment were also explored.

\section{METHODS}

\section{Study Design and Patients}

The study design, patients, methodology and statistical analysis of the MEASURE 1 (ClinicalTrials.gov: NCT01358175) and 2 (ClinicalTrials.gov: NCT01649375) studies have been described previously $[17,19,20]$. Briefly, MEASURE 1 was a 2-year phase 3 study followed by a 3-year extension study (ClinicalTrials.gov: NCT01863732), wherein 371 patients were randomly allocated to receive intravenous loading doses of secukinumab $(10 \mathrm{mg} / \mathrm{kg})$ or placebo at baseline and weeks 2 and 4, followed by subcutaneous (s.c.) maintenance dosing of secukinumab $150 \mathrm{mg}$, $75 \mathrm{mg}$, or placebo every 4 weeks ( $\mathrm{q} 4 \mathrm{w})$ starting at week 8. Based on ASAS20 improvement (20\% improvement) in at least three of four domains, clinical response at week 16, placebo-treated patients were re-randomized to receive s.c. secukinumab $150 \mathrm{mg}$ or $75 \mathrm{mg}$ at week 16 (ASAS20 non-responders) or week 24 (ASAS20 responders) [17, 20]. MEASURE 2 is a 5-year phase 3 study, wherein 222 patients received s.c. loading and maintenance dosing of secukinumab $150 \mathrm{mg}, 75 \mathrm{mg}$, or placebo at baseline and weeks 1,2 , and 3 , followed by $\mathrm{q} 4 \mathrm{w}$ starting at week 4 . At week 16 , placebotreated patients were re-randomized to s.c. secukinumab $150 \mathrm{mg}$ or $75 \mathrm{mg} \mathrm{q} 4 \mathrm{w}$, regardless of clinical response $[17,19]$. In both studies, patients aged $\geq 18$ years with active AS fulfilling the modified New York Criteria [23], with a BASDAI score $\geq 4$ [24] and a spinal pain score $\geq 40 \mathrm{~mm}$ on a $100 \mathrm{~mm}$ visual analog scale despite treatment with nonsteroidal anti-inflammatory drugs, were included. Patients with an IR or intolerance to not more than one TNFi were included in the study. Exclusion criteria have been published previously $[17,19,20]$. 
MEASURE 1 and 2 studies were conducted in accordance with the principles of the Declaration of Helsinki (as revised in Brazil 2013), and all centers received approval from independent ethics committees or institutional review boards (see Electronic Supplementary Material [ESM]). Written informed consent was provided by all enrolled patients [25]. All human research procedures followed were in accordance with the principles of the Declaration of Helsinki (as revised in Brazil 2013). No protected health information of research participants are disclosed in the current manuscript.

\section{Outcome Measures}

The following measures were assessed: ASDASID (score $<1.3$ ) [26], ASAS-PR (score $\leq 2$ in each of the 4 main ASAS domains) [27], or BASDAI $\leq 2$. Patients were characterized as achieving or not achieving remission based on achieving ASDAS-ID, ASAS-PR, or BASDAI $\leq 2$. The proportion of patients who achieved ASDAS-ID, ASAS PR, or BASDAI $\leq 2$ with secukinumab treatment was compared with those receiving placebo up to week 16 . The proportion of patients achieving and maintaining remission with secukinumab up to week 156 was also explored. Sustained remission at week 104 was defined as maintaining the same state at week 104 as that of the previous time points (weeks 16 and 52). Similarly, sustained ASDAS-ID, ASAS-PR, or BASDAI state at week 156 was defined as maintaining the same clinical state at week 156 as that of the previous time points (weeks 16, 52, and 104).

The PRO measures included the following assessment tools: Bath AS Functional Index (BASFI) [28], AS Quality of Life (ASQoL) measure [29], Functional Assessment of Chronic Illness Therapy (FACIT)-Fatigue scale [30], Short-Form 36 (SF-36) Physical Component Summary (PCS) score, SF-36 Mental Component Summary (MCS) score [31], and Work Productivity and Activity Impairment-General Health measure (WPAI-GH) [32]. BASFI was assessed at baseline and at weeks 1,2 , and 4 , then $\mathrm{q} 4 \mathrm{w}$ to week 32 , and then every 8 weeks up to week 156. All other PROs were assessed at baseline and at weeks $4,8,12,16,24,52,104$, and 156 , with the exception of WPAI-GH, which was assessed at baseline and at weeks 16, 24, and 52, and ASQoL, which was not assessed after week 104 in MEASURE 1 and week 52 in MEASURE 2, as per the respective study protocol.

\section{Statistical Analyses}

All analyses used pooled data from the MEASURE 1 and 2 studies for the overall sample population (originally randomized patients) and stratified by TNFi status (naïve or IR) at baseline, unless otherwise specified. Data are reported only for the approved initiation dose (150 mg) of secukinumab.

Achieving remission was used as a binary outcome. Patients were characterized as achieving or not achieving remission based on achieving ASDAS-ID, ASAS-PR, or BASDAI $\leq 2$.

Shift analysis on ASDAS status from week 16 to 156 included the following ASDAS disease activity states based on validated criteria: very high disease activity (VHDA), $>3.5$; high disease activity 2.1-to 3.5; LDA, 1.3 to $<2.1$; and ID, $<1.3[26,33]$. Sustainability of ASAS-PR at the individual patient level was assessed between week 16 and weeks 104 and 156 [7]. Shift analysis on BASDAI states from week 16 to 156 was based on following (non-validated) threshold criteria ( $\geq 4, \geq 3$ to $<4,>2$ to $<3$, and $\leq 2$ ).

Comparisons of secukinumab versus placebo for achieving remission were performed up to week 16, using Fisher's exact test. Analysis of continuous variables used mixed-effect model repeated measures ([MMRM] with Gaussian error distribution and missing at random assumption). For each PRO, the change from baseline up to week 156 was explored by the defined remission state using MMRM measures, with remission state, analysis visit, and randomization strata (TNFi status: naïve or IR) as factors and weight and baseline score as continuous covariates. Remission status by analysis visit was included as an interaction term, and an unstructured covariance structure was assumed for this model. Remission status variables included ASDAS C-reactive protein 
(ASDAS-CRP $<1.3$ ), BASDAI $\leq 2$, and ASAS-PR. Remission status was defined as an indicator variable with value of Yes vs. No (or 1 vs. 0 ) to assess the association of remission on change in PRO. The association between remission status and PROs were tested with MMRM-based $t$ tests. The model-based estimates for the individual remission status coefficients were derived together with 95\% confidence intervals (CI) and $P$ values.

\section{RESULTS}

The details of patient disposition and retention rates in the MEASURE 1 and 2 studies through week 156 have been reported previously [18, 19]. In this analysis, 197 and 196 patients were included in the pooled secukinumab $150 \mathrm{mg}$ and placebo groups, respectively. Only the patients who received secukinumab $150 \mathrm{mg}$ were included in the current pooled analysis. Baseline demographic and clinical characteristics were balanced across the secukinumab and placebo groups and are shown in Table 1 .

\section{Remission Status}

At week 16, a higher proportion of secukinumab-treated patients achieved ASDAS-ID, ASAS-PR, and BASDAI $\leq 2$ compared with placebo (ASDAS-ID: 17.6 vs. $3.5 \%, P<0.0001$; ASAS-PR: 15.4 vs. $4.1 \%, P<0.001$; BASDAI $\leq 2$ : 22.3 vs. $6.4 \%, P<0.0001)$. The proportion of secukinumab-treated patients achieving either ASDAS-ID, ASAS-PR, or BASDAI $\leq 2$ was sustained to 156 weeks (Fig. 1). Similarly, a higher proportion of secukinumab-treated patients achieved ASDAS-ID, ASAS-PR, and BASDAI $\leq 2$ at week 16 in the TNFi-naïve group versus placebo (ASDAS-ID: 18.9 vs. $4.1 \%, P<0.001$; ASASPR: 17.4 vs. $5.7, P<0.05$; BASDAI $\leq 2$ : 25.8 vs. $8.2 \%, P<0.001)$. For TNFi-IR patients, the proportion of patients with ASDAS-ID, ASAS-PR, and $\mathrm{BASDAI} \leq 2$ treated with secukinumab was $14.5,10.7$, and $14.3 \%$, respectively, versus 2.0 , 0.0 , and $2.0 \%$, respectively, in the placebo group $(P<0.05$ vs. placebo for all 3 responses/ states; Fig. 2). These responses were sustained through week 156 in both TNFi -naive and -IR patients (Fig. 2).

The shift analysis from week 16 to week 104 showed that the majority of secukinumab-treated patients who achieved ASDAS-ID at week 16 maintained ID $(60.7 \%)$ or had LDA $(25 \%)$ at week 104. Analysis from weeks 16 to 156 showed that $57.1 \%$ patients maintained ID, with $14.3 \%$ having LDA. Overall, $85.1 \%$ of patients with LDA at week 16 maintained or improved their status to ID at week 104. Similarly, $64.7 \%$ of patients with LDA at week 16 maintained or improved their status to ID at week 156 (Fig. 3a). The majority of patients with ASAS-PR at week 16 maintained their response from week 16 to weeks 104 (80.0\%) and 156 (68.0\%) (Fig. 3b). The shift analysis from weeks 16 to 104 showed that the majority of secukinumab-treated patients who achieved BAS$\mathrm{DAI} \leq 2$ at week 16 maintained their status $(79.4 \%)$ or had $2<$ BASDAI $<3(20.6 \%)$ at week 104; at week $156,74.3 \%$ maintained BASDAI $\leq 2$ and $17.1 \%$ had $2<$ BASDAI $<3$. A total of 69.5 and $70 \%$ of patients with $2<$ BASDAI $<3$ at week 16 maintained or improved to BASDAI $\leq 2$ at weeks 104 and 156, respectively (Fig. 3c).

The shift analysis was also performed in TNFi subgroups (TNFi-naïve vs. TNFi-IR) through week 156 (ESM Fig. 1). The majority of patients (in both the overall population and TNFi subgroups) who had ASDAS-VHDA or BASDAI $\geq 4$ status at week 16 improved their disease activity status at week 156 (Figs. 2, 3; ESM Fig. 1).

\section{Association Between Remission Status and PROs}

At week 156, the ASDAS-ID was found to have a significant association (in terms of change from baseline [coefficient in MMRM]; 95\% CI) with BASFI ( $-0.9 ; 95 \% \mathrm{CI}-1.29$ to -0.43$)$, ASQoL (-2.3; 95\% CI - 3.71 to -0.87$)$, SF-36 PCS (3.7; $95 \%$ CI 1.68 to 5.69 ), and WPAI-GH (- 16.7; $95 \%$ CI -25.64 to -7.82 ). The co-efficients of BASFI, ASQoL, and WPAI-GH, respectively, were all negative in patients with ASDAS-ID, indicating a low degree of functional limitation, good QoL, and lower impairments in work and activities. However, no significant association 
Table 1 Baseline demographic and clinical characteristics

\begin{tabular}{|c|c|c|}
\hline Baseline demographic and clinical characteristics & $\begin{array}{l}\text { Pooled secukinumab } 150 \mathrm{mg} \\
(N=197)^{\mathrm{a}}\end{array}$ & $\begin{array}{l}\text { Pooled placebo } \\
(N=196)^{\mathrm{a}}\end{array}$ \\
\hline Age (years), mean (SD) & $40.8(11.9)$ & $43.3(12.7)$ \\
\hline Male, $n(\%)$ & $130(66.0)$ & $141(71.9)$ \\
\hline Weight $(\mathrm{kg})$, mean $(\mathrm{SD})$ & $77.5(17.2)$ & $78.0(14.8)$ \\
\hline BMI $\left(\mathrm{kg} / \mathrm{m}^{2}\right)$, mean $(\mathrm{SD})$ & $26.8(5.4)$ & $26.7(5.1)$ \\
\hline \multicolumn{3}{|l|}{ Prior TNFi status, $n(\%)$} \\
\hline Naïve & $136(69.0)$ & $134(68.4)$ \\
\hline Inadequate responder & $61(31.0)$ & $62(31.6)$ \\
\hline Time since first diagnosis of AS (years), $n$ & 195 & 195 \\
\hline Mean (SD) & $6.7(7.4)$ & $7.6(8.9)$ \\
\hline Smoking history, $n$ (\%) & $85(43.1)$ & $92(46.9)$ \\
\hline Methotrexate use at randomization, $n(\%)$ & $25(12.7)$ & $25(12.8)$ \\
\hline CRP (mg/L), mean (SD) & $20.2(35.2)$ & $16.4(20.9)$ \\
\hline DAS28-CRP, $n$ & 197 & 195 \\
\hline Mean score (SD) & $3.6(0.9)$ & $3.8(0.9)$ \\
\hline BASDAI score, $n$ & 197 & 196 \\
\hline Mean score (SD) & $6.4(1.5)$ & $6.6(1.4)$ \\
\hline BASFI score, $n$ & 197 & 195 \\
\hline Mean score (SD) & $5.9(2.2)$ & $5.9(2.0)$ \\
\hline ASQOL score, $n$ & 196 & 194 \\
\hline Mean score (SD) & $11.3(4.5)$ & $11.6(4.2)$ \\
\hline FACIT-Fatigue score, $n$ & 197 & 195 \\
\hline Mean score (SD) & $24.5(10.2)$ & $24.4(9.2)$ \\
\hline SF-36: PCS, $n$ & 197 & 195 \\
\hline Mean score (SD) & $35.94(6.8)$ & $36.27(6.3)$ \\
\hline SF-36: MCS, $n$ & 197 & 195 \\
\hline Mean score (SD) & $39.9(10.6)$ & $39.5(10.4)$ \\
\hline $\begin{array}{l}\text { WPAI-GH: percentage work time missed due to health } \\
n\end{array}$ & 125 & 117 \\
\hline Mean (SD) & $12.4(22.4)$ & $16.2(27.4)$ \\
\hline $\begin{array}{l}\text { WPAI-GH: percentage impairment while working due to } \\
\text { health }^{\text {b }, n}\end{array}$ & 122 & 111 \\
\hline Mean (SD) & $46.6(23.7)$ & $52.0(20.9)$ \\
\hline
\end{tabular}


Table 1 continued

\begin{tabular}{lll}
\hline Baseline demographic and clinical characteristics & $\begin{array}{l}\text { Pooled secukinumab 150 mg } \\
(\boldsymbol{N}=\mathbf{1 9 7})^{\mathbf{a}}\end{array}$ & $\begin{array}{l}\text { Pooled placebo } \\
(\boldsymbol{N}=\mathbf{1 9 6})^{\mathbf{a}}\end{array}$ \\
\hline $\begin{array}{l}\text { WPAI-GH: percentage overall work impairment due to } \\
\text { health }^{\text {b }}, n\end{array}$ & 122 & 112 \\
Mean (SD) & $51.2(25.9)$ & $57.2(22.7)$ \\
$\begin{array}{l}\text { WPAI-GH: percentage activity impairment due to } \\
\text { health }{ }^{\text {b }},\end{array}$ & 193 & 195 \\
Mean (SD) & $58.3(22.2)$ & $59.5(21.6)$ \\
Total back pain (VAS, 0-100 mm), $n$ & 197 & 196 \\
Mean VAS score (SD) & $64.8(17.9)$ & $67.7(17.4)$ \\
Nocturnal back pain (VAS, 0-100 mm), $n$ & 197 & 196 \\
Mean VAS score (SD) & $62.6(19.1)$ & $64.8(19.6)$ \\
PGA of disease activity (VAS, 0-100), $n$ & 197 & 196 \\
Mean VAS score (SD) & $65.2(18.6)$ & $67.9(17.7)$ \\
\hline
\end{tabular}

$A S$ ankylosing spondylitis, $A S Q D L$ Ankylosing Spondylitis Quality of Life, BASDAI Bath Ankylosing Spondylitis Disease Activity Index, BASFI Bath Ankylosing Spondylitis Functional Index, DAS28-CRP Disease Activity Score 28 joints-C-reactive protein, $M C S$ mental component summary, $N$ total number of patients in the cohort, $n$ number of patients with response, $P C S$ physical component summary, $P G A$ Patient's Global Assessment, $S F-36$ Short-Form Health Survey-36 Item, $S D$ standrad deviation, TNFi tumor necrosis factor inhibitor, VAS Visual Analog Scale, WPAI-GH Work Productivity and Activity Impairment Questionnaire-General Health

${ }^{a}$ Data are pooled from the MEASURE 1 and 2 studies

b WPAI-GH work time missed, impairment while working, and overall work impairment, includes employed patients only

was observed between ASDAS-ID and FACIT-fatigue or SF-36 MCS. At week 156, ASAS-PR and BASDAI $\leq 2$ had a significant association with all PROs (Fig. 4).

\section{DISCUSSION}

Although an internal task force has recommended a T2T strategy, with ASDAS as the suggested tool for the management of axSpA [4], a lack of evidence from RCTs for the added value of a T2T strategy in axSpA and the lack of universally accepted remission criteria are major barriers to the implementation of a T2T approach in axSpA [7-9]. Recently, ASDAS-ID (score $<1.3$ ) has been recommended as a preferred measure for remission in AS since it is a composite index with validated cutoffs, including an objective marker of inflammation (C-reactive protein) [4, 34]. However, this measure is still not universally adopted. In 2001, the ASAS developed a tool that includes a preliminary definition of clinical remission (ASAS-PR), with assessment of four domains, namely, patient global assessment of disease activity, spinal pain, physical function, and spinal inflammation (based on duration and severity of morning stiffness), without any assessment of CRP levels [35]. BASDAI is another widely used index in both clinical trials and clinical practice $[4,8]$ and, therefore, we included the criteria of this tool in this analysis. There is no defined clinical remission criteria for BASDAI, and BASDAI $<3, \leq 3$, or $<4$ have been used in clinical trials to define clinical remission or LDA; however, none of these thresholds have been validated $[7,14,36-38]$. In the present 


\section{A. ASDAS-ID}

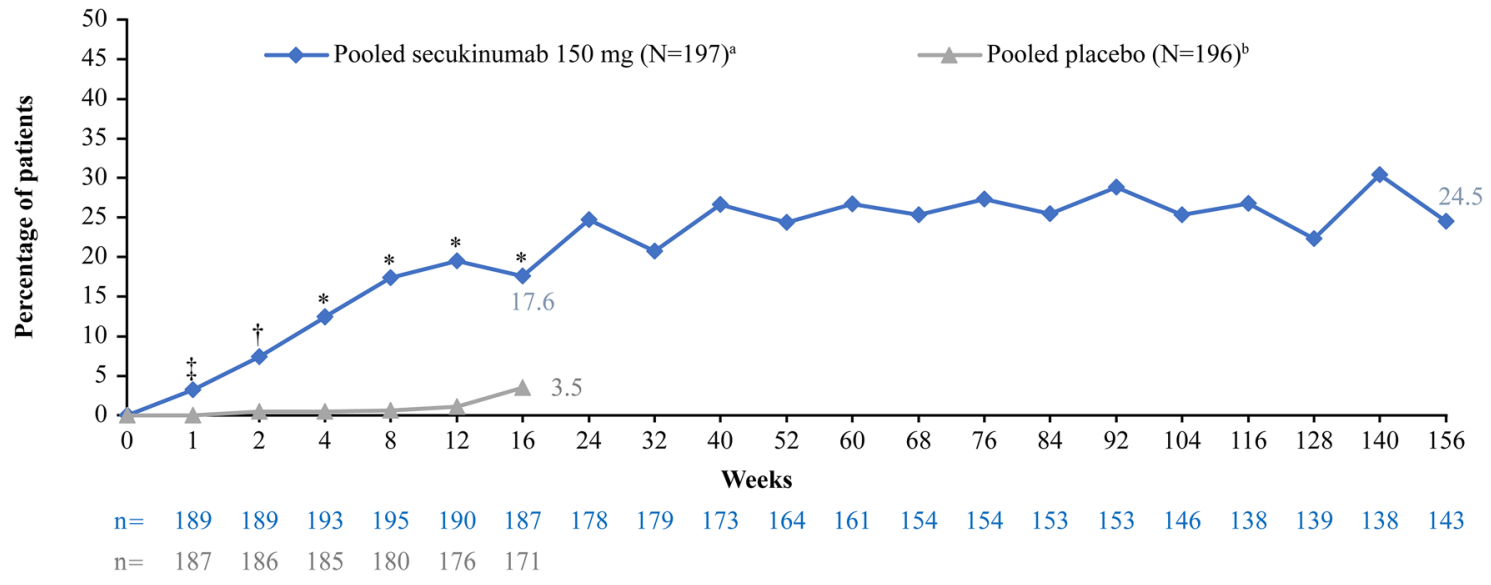

\section{B. ASAS-PR}

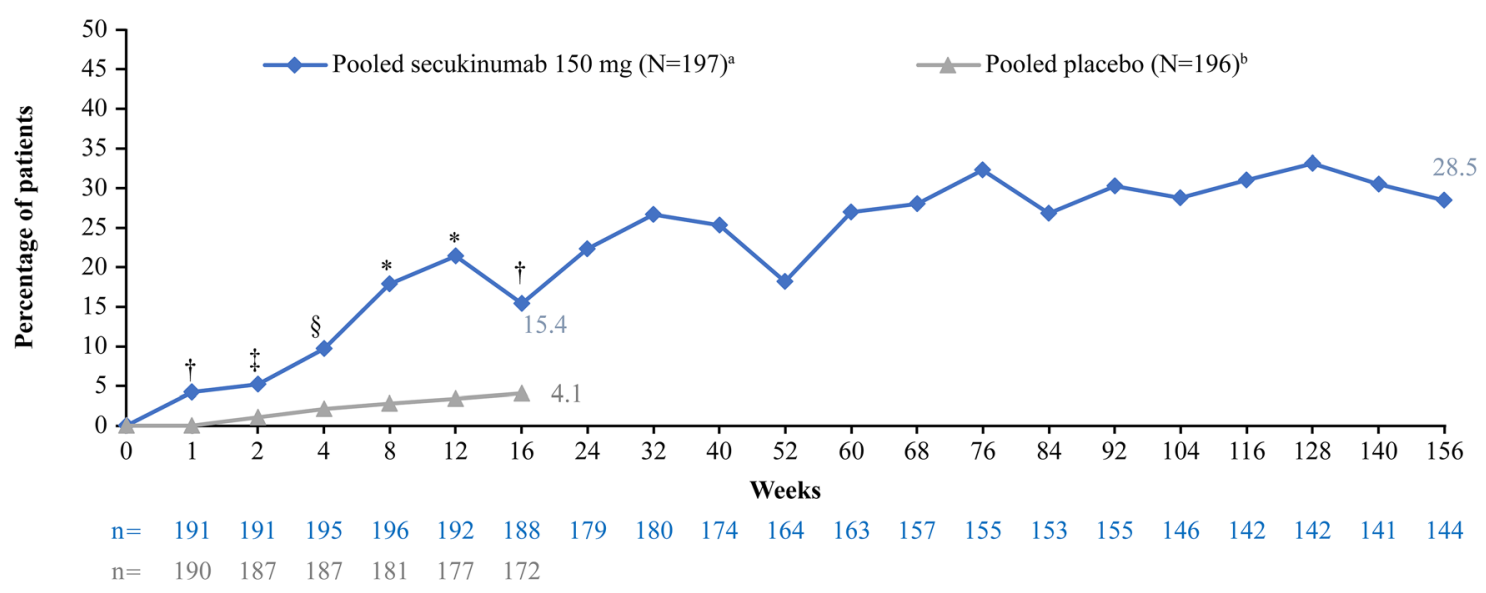

\section{BASDAI $\leq 2$}

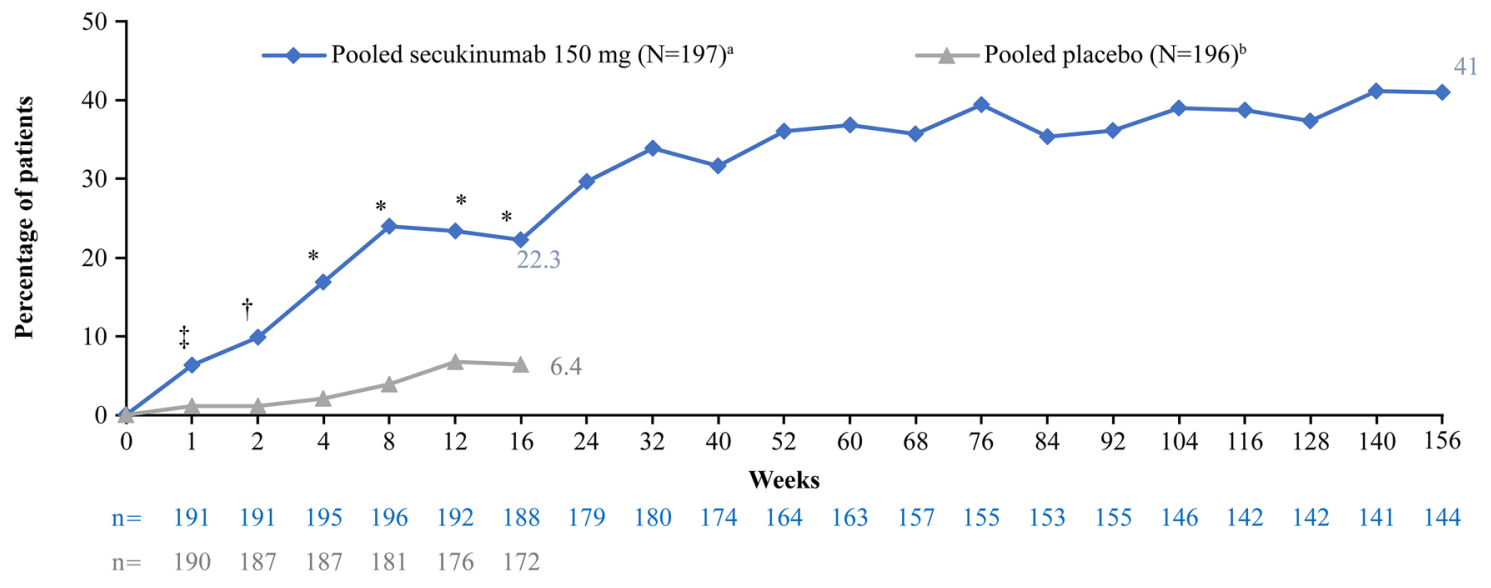


4Fig. 1 Proportion of patients with ASDAS-ID, ASAS-PR and BASDAI $\leq 2$ through week 156 (FAS). Analysis is based on observed data. ${ }^{a} N=159$ after week 104, ${ }^{\mathrm{b}} N=161$ after week 104. ${ }^{*} P<0.0001,{ }^{\dagger} P<0.001$, ${ }^{\S} P<0.01$, and ${ }^{\ddagger} P<0.05$ versus placebo; $P$ values are from Fisher's exact test and are displayed up to week 16, prior to placebo re-randomization. $N=$ number of patients included in the analysis, $n=$ number of evaluable patients. $A S A S-P R$ Assessment of SpondyloArthritis international Society criteria for partial remission, $A S D A S-I D$ Ankylosing Spondylitis Disease Activity Score for inactive disease, BASDAI Bath Ankylosing Spondylitis Disease Activity Index, $F A S$ full analysis set

analysis, BASDAI $\leq 2$, was used as an exploratory measure of remission, as it would be a pragmatic tool to assess remission in clinical practice.

The current analyses showed that 17.6, 15.4, and $22.3 \%$ of patients achieved ASDAS-ID, ASAS-PR and BASDAI $\leq 2$ at week 16 , which was sustained for up to 3 years of treatment with secukinumab. The proportion of secukinumabtreated patients with ASDAS-ID, ASAS-PR, or BASDAI $\leq 2$ showed similar trends among TNFinaïve and TNFi-IR groups, with a higher proportion in the TNFi-naive group achieving ID or remission. Shift analysis showed that the majority of secukinumab-treated patients achieving LDA or remission state at week 16 improved or maintained their status at week 156. Comparable results were observed in patients with AS treated with TNFi, with TNFinaïve patients initiating treatment with adalimumab, infliximab, etanercept, and golimumab showing improvements in ASDAS-ID and ASASPR status after 12 or 24 weeks of treatment [39-43]. Similarly, treatment with certolizumab resulted in improvements in ASDAS-ID and ASAS-PR at week 12 in TNFi-naïve patients or patients who discontinued TNFi due to secondary treatment failure in AS [44]. A long-term study on infliximab showed that patients with AS achieved ASAS-PR after 3 years of treatment [45].

A previous report from the MEASURE 1 study showed that sustained long-term efficacy was associated with improvement in physical function, HRQoL, pain, fatigue, and work productivity in patients with AS treated with secukinumab for 52 weeks [46]. In this post hoc analysis, we found that ASDAS-ID, ASAS-PR, or BASDAI $\leq 2$ were associated with the majority of PROs. Physical health status, HRQoL, functional impairment, and work productivity improved from baseline to 156 weeks in secukinumab-treated patients with AS who achieved these remission criteria. Mental health status and fatigue levels did not show an association with ASDAS-ID; however, both of these PROs were associated with ASAS-PR and BASDAI $\leq 2$.

\section{Limitations}

There is conflicting data in the literature regarding the use of ASAS-PR as a target for remission in contrast to ASDAS-ID in clinical trials. The strength of this exploratory analysis included exploring achievement of ASDAS-ID together with ASAS-PR and an exploratory target of $\mathrm{BASDAI} \leq 2$ using secukinumab data from clinical trials in axSpA. However, the fact that ASAS-PR and BASDAI $\leq 2$ are not validated remission targets is a limitation of this analysis. Further limitations are that analyses were posthoc and there was no placebo arm beyond week 16.

\section{CONCLUSION}

In this pooled analysis, most secukinumabtreated patients who achieved LDA or inactive disease related to either ASDAS, ASAS-PR or BASDAI $\leq 2$ at week 16 maintained their status up to week 156 at an individual level. The findings with BASDAI were consistent with those of ASDAS-ID and ASAS-PR, suggesting that BASDAI $\leq 2$ might be considered as a useful disease activity index to measure remission in patients with AS in clinical practice; consequently further study and validation are needed. Patients who achieved a remission status at week 156 also reported improvement in physical function, HRQoL, and work productivity, which indicates an association between clinical remission and PROs in patients with active AS. 


\section{A. ASDAS-ID}

TNFi- naïve

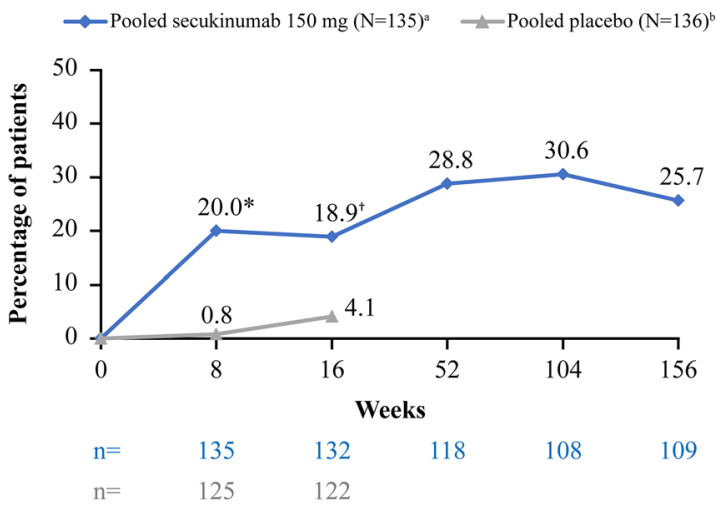

\section{B. ASAS-PR}

TNFi- naïve

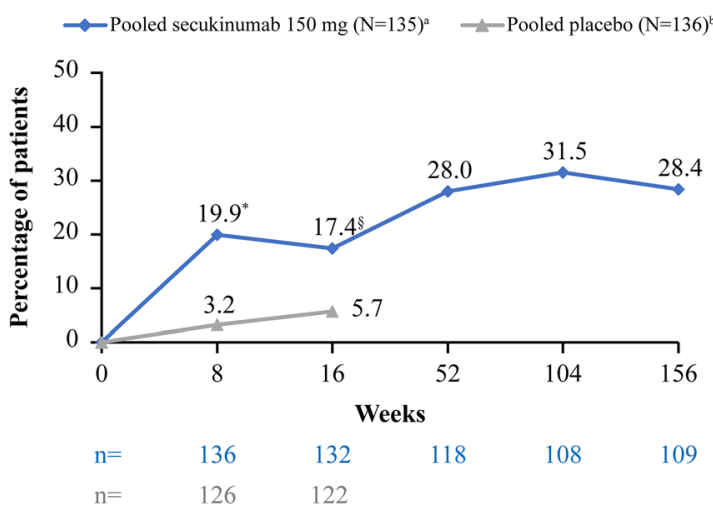

\section{BASDAI $\leq 2$}

\section{TNFi- naïve}

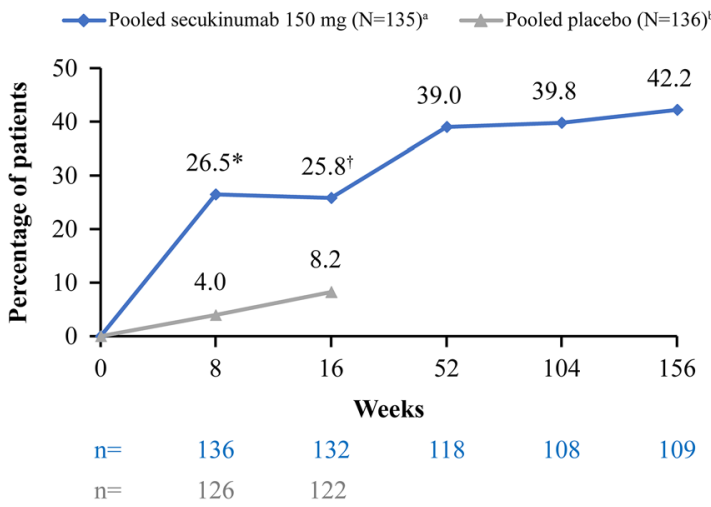

\section{TNFi-IR}
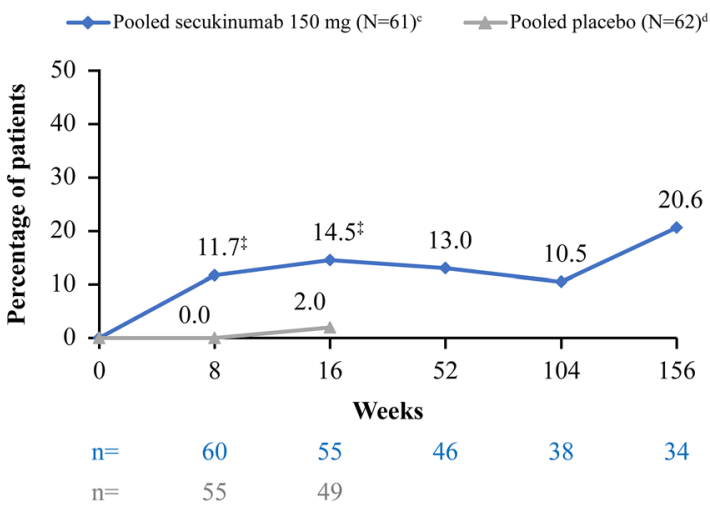

\section{TNFi-IR}

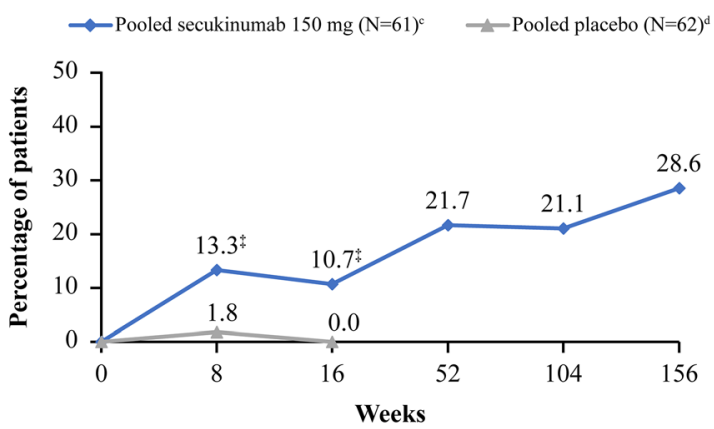

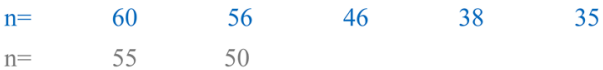

\section{TNFi-IR}

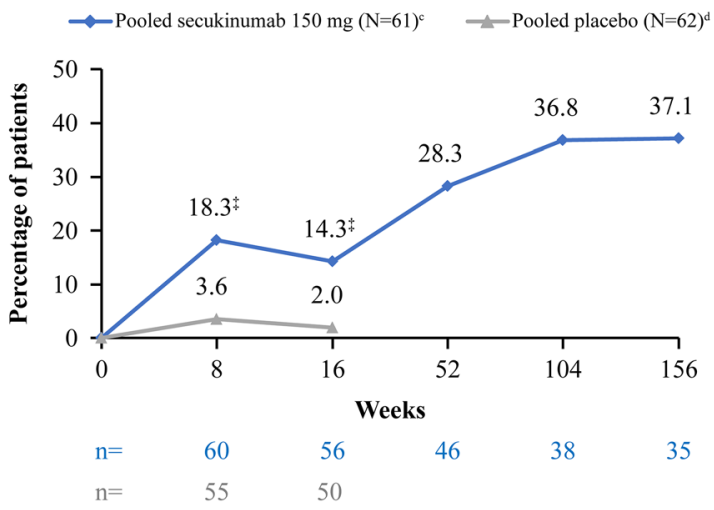


4Fig. 2 Proportion of patients with ASDAS-ID, ASAS-PR, and BASDAI $\leq 2$ through week 156 (by TNFi status). Analysis based on observed data. ${ }^{a} N=114$ after week 104 , ${ }^{\mathrm{b}} N=114$ after week $104,{ }^{\mathrm{c}} N=45$ after week 104 , ${ }^{\mathrm{d}} N=47$ after week 104. ${ }^{*} P<0.0001,{ }^{\dagger} P<0.001$, ${ }^{\S} P<0.01,{ }^{\ddagger} P<0.05$ versus placebo; $P$ values are from Fisher's exact test and are displayed up to week 16 , prior to placebo re-randomization. $N=$ number of patients included in the analysis, $n=$ number of evaluable patients. $I R$ Inadequate response, $P R$ partial remission, $T N F i$ tumor necrosis factor inhibitor

\section{ACKNOWLEDGEMENTS}

The study was designed by the scientific steering committee and Novartis personnel. Medical writing support was funded by Novartis. The authors thank the patients who participated in this study, the study investigators and John Gallagher, Novartis Pharmaceuticals UK Ltd., for medical guidance and editorial support. PMM is supported by the University College London Hospital (UCLH) Biomedical Research Centre (BRC). HMO is supported by the National Institute for Health Research (NIHR) Leeds Biomedical Research Centre (LBRC). The views expressed are those of the authors and not necessarily those of the (UK) National Health Service (NHS), the NIHR, or the (UK) Department of Health.

Funding. This study and the journal's Rapid Service Fee was funded by Novartis Pharma AG, Basel, Switzerland.

Medical Writing, Editorial, and Other Assistance. Manuscript writing support, under the guidance of the authors, was provided by Amit Agarwal and Dhanya Mukundan, Novartis Healthcare Pvt Ltd, Hyderabad, India. Medical writing support was funded by Novartis.

Authorship. All named authors meet the International Committee of Medical Journal Editors (ICMJE) criteria for authorship for this article, take responsibility for the integrity of the work as a whole, and have given their approval for this version to be published.
Disclosures. Xenofon Baraliakos has received grant and research support fees from AbbVie, Novartis; consultancy fees from AbbVie, BMS, Celgene, Chugai, Merck, Novartis, Pfizer, UCB, Werfen; and speakers bureau fees from AbbVie, BMS, Celgene, Chugai, Merck, Novartis, Pfizer, and UCB. Filip Van den Bosch has received consulting fees from and is a member of the speaker's bureau of AbbVie, Celgene, Janssen, Eli Lilly, Galapagos, Merck, Novartis, Pfizer, and UCB Pharma. Pedro M. Machado has received consulting/speaker's fees from Abbvie, BMS, Celgene, Eli Lilly, Janssen, MSD, Novartis, Pfizer, Roche and UCB. Lianne S. Gensler reports research grants from AbbVie, Amgen, Eli Lilly and Company, Novartis, Pfizer, and UCB Pharma; and consultancy fees from AbbVie, Eli Lilly and Company, Galapagos, GlaxoSmithKline, Janssen, Novartis, Pfizer, and UCB Pharma. Helena Marzo-Ortega reports research funds from Janssen and Novartis, and consulting and speaking fees from AbbVie, Celgene, Janssen, Eli Lilly and Company, Novartis, Pfizer, Takeda, and UCB. Bintu Sherif has received consulting fees from Novartis through employment at RTI Health Solutions. Erhard Quebe-Fehling, Brian Porter, and Corine Gaillez are employees and shareholders of Novartis. Corine Gaillez also holds BMS shares. Atul Deodhar reports consulting fees and advisory board fees from AbbVie, Amgen, Boehringer Ingelheim, Celgene, Eli Lilly, Galapagos, Glaxo Smith \& Kline, Janssen, Novartis, Pfizer, UCB; and research grants from AbbVie, Eli Lilly, Glaxo Smith \& Kline, Novartis, Pfizer, UCB.

Compliance with Ethics Guidelines. MEASURE 1 and 2 studies were conducted in accordance with the principles of the Declaration of Helsinki (as revised in Brazil 2013), and all centers received approval from independent ethics committees or institutional review boards (see Electronic Supplementary Material). Written informed consent was provided by all enrolled patients. All human research procedures followed were in accordance with the principles of the Declaration of Helsinki (as revised in Brazil 2013). 


\section{A. Shift in ASDAS status from Week 16}

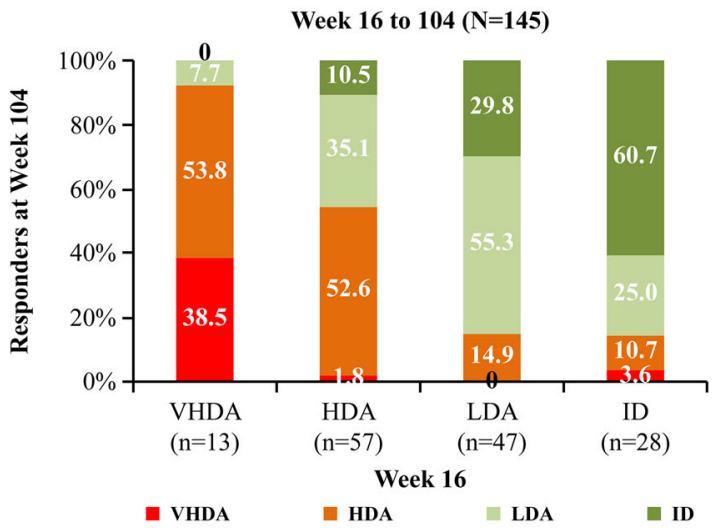

\section{B. Shift in ASAS-PR from Week 16}

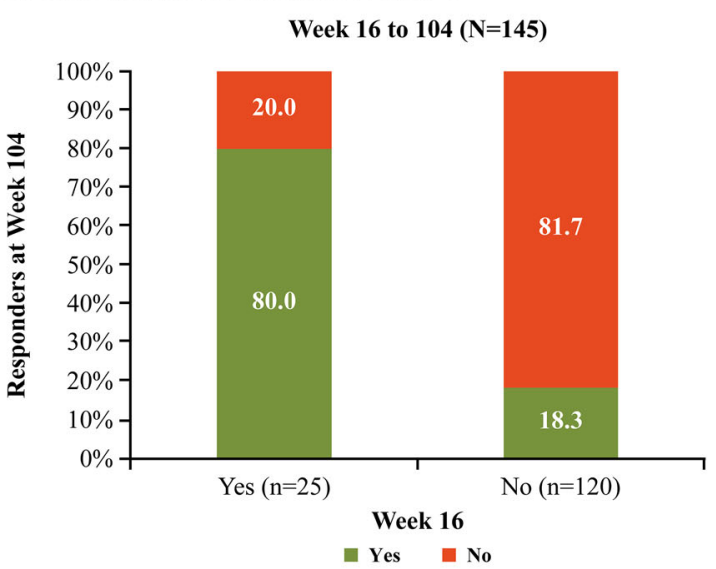

\section{Shift in BASDAI status from Week 16}

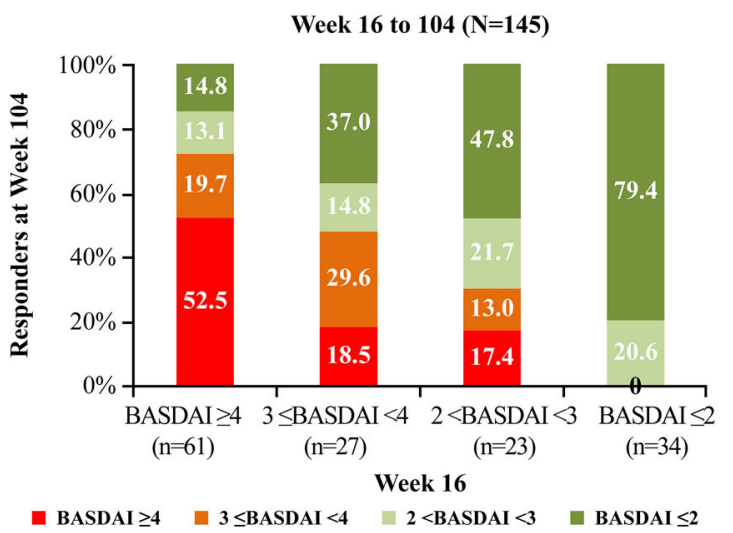

Fig. 3 Shift analysis from week 16. Proportion of patients with ASDAS-ID, ASAS-PR, and BASDAI $\leq 2$ responses at weeks 104 or 156. Shift analysis was performed on mutually exclusive categories in patients for whom data were available at both week 16 and weeks 104 or 156 . $N=$ total number of patients included in the analysis,
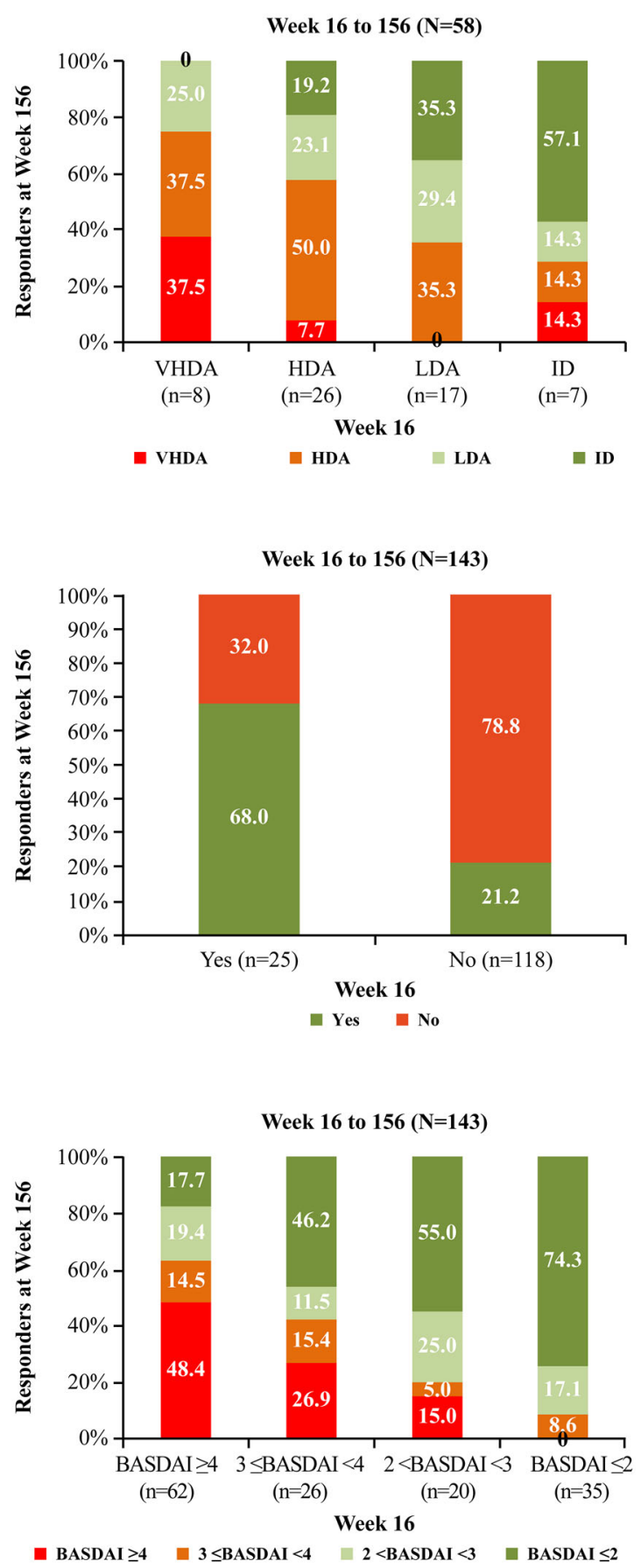

$n=$ number of evaluable patients who completed week 16 . $H D A$ High disease activity $(2.1-3.5), I D$ inactive disease $(<1.3)$; LDA, low disease activity $(1.3$ to $<2.1), V H D A$ very high disease activity $(>3.5)$ 


\section{A. ASDAS-ID and PROs}

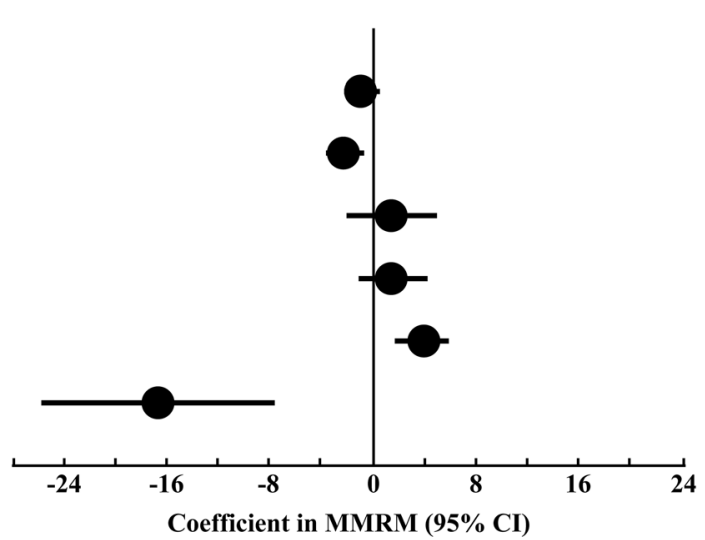

B. ASAS-PR and PROs

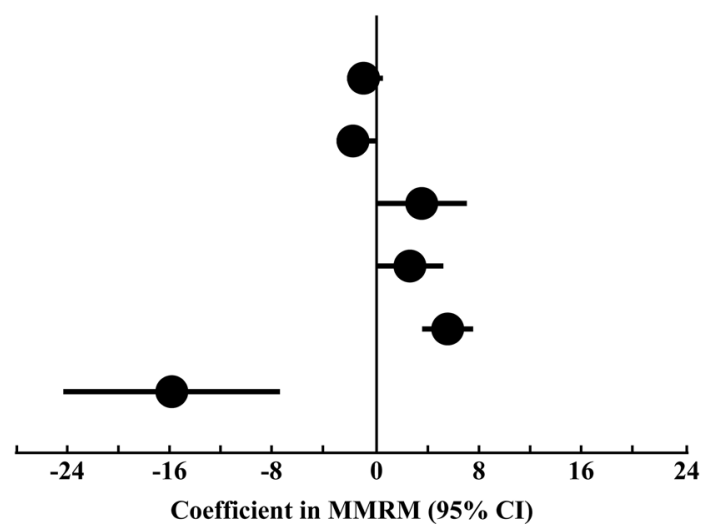

C. BASDAI $\leq 2$ and PROs

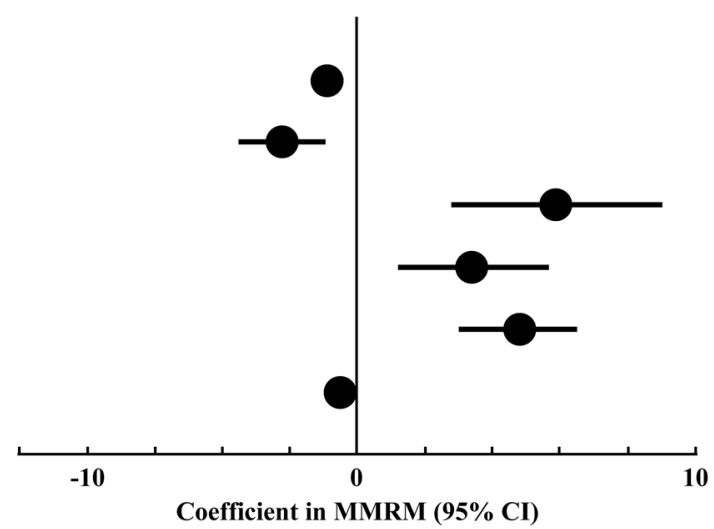

Variables

$-0.9(-1.29,-0.43)$

$-2.3(-3.71,-0.87)$

$1.4(-2.09,4.88)$

$1.4(-1.21,4.09)$

$3.7(1.68,5.69)$

$-16.7(-25.64,-7.82)$

$-1.0(-1.43,-0.66)$

$-1.9(-3.21,-0.51)$

$3.5(0.31,6.79)$

$2.7(0.25,5.17)$

$5.4(3.53,7.19)$

$-15.8(-24.02,-7.59)$

$-0.9(-1.25,-0.54)$

$-2.2(-3.51,-0.96)$

$5.9(2.82,9.02)$

$3.4(1.15,5.67)$

$4.8(3.04,6.53)$

$-0.5(-0.65,-0.44)$
BASFI

ASQoL

FACIT-Fatigue

SF-36 MCS

SF-36 PCS

WPAI-GH (activity impairment)
Variables

BASFI

ASQoL

FACIT-Fatigue

SF-36 MCS

SF-36 PCS

WPAI-GH (activity impairment)
Variables

BASFI

ASQoL

FACIT-Fatigue

SF-36 MCS

SF-36 PCS

WPAI-GH (activity impairment) 
4 Fig. 4 Association of ASDAS-ID, ASAS-PR, and BASDAI $\leq 2$ with PROs (change from baseline to 156 weeks; coefficient in MMRM). Data are from MMRM, with analysis visit and TNFi status (overall pooled sample only) as factors, and weight, baseline score, and remission status as continuous covariates. Remission status by analysis visit is included as an interaction term in the model. An unstructured covariance structure is used for this model. ASQoL Ankylosing spondylitis (AS) Quality of Life, $B A S F I$ Bath AS Functional Index, $C I$ confidence interval, FACIT Functional Assessment of Chronic Illness Therapy, MCS mental component summary of SF-36, MMRM mixed-effects models for repeated measures, $P C S$ physical component summary of SF-36, PROs patient-reported outcomes, SF-36 Short-Form 36 health survey, WPAI-GH Work Productivity and Activity Impairment-General Health

Data Availability. The datasets generated during and/or analyzed during the current study are not publicly available. Novartis is committed to sharing with qualified external researchers' access to patient-level data and supporting clinical documents from eligible studies. These requests are reviewed and approved on the basis of scientific merit. All data provided is anonymized to respect the privacy of patients who have participated in these trials in line with applicable laws and regulations. The data may be requested from the corresponding author of the manuscript.

Open Access. This article is licensed under a Creative Commons Attribution-NonCommercial 4.0 International License, which permits any non-commercial use, sharing, adaptation, distribution and reproduction in any medium or format, as long as you give appropriate credit to the original author(s) and the source, provide a link to the Creative Commons licence, and indicate if changes were made. The images or other third party material in this article are included in the article's Creative Commons licence, unless indicated otherwise in a credit line to the material. If material is not included in the article's Creative Commons licence and your intended use is not permitted by statutory regulation or exceeds the permitted use, you will need to obtain permission directly from the copyright holder. To view a copy of this licence, visit http://creativecommons.org/licenses/bync/4.0/.

\section{REFERENCES}

1. Braun J, Sieper J. Ankylosing spondylitis. Lancet. 2007;369(9570):1379-90.

2. Dougados M, Baeten D. Spondyloarthritis. Lancet. 2011;377(9783):2127-37.

3. Gao X, Wendling D, Botteman MF, Carter JA, Rao S, Cifaldi M. Clinical and economic burden of extraarticular manifestations in ankylosing spondylitis patients treated with anti-tumor necrosis factor agents. J Med Econ. 2012;15(6):1054-63.

4. Smolen JS, Schols M, Braun J, et al. Treating axial spondyloarthritis and peripheral spondyloarthritis, especially psoriatic arthritis, to target: 2017 update of recommendations by an international task force. Ann Rheum Dis. 2018;77(1):3-17.

5. Poddubnyy D, Protopopov M, Haibel H, Braun J, Rudwaleit M, Sieper J. High disease activity according to the Ankylosing Spondylitis Disease Activity Score is associated with accelerated radiographic spinal progression in patients with early axial spondyloarthritis: results from the GErman SPondyloarthritis Inception Cohort. Ann Rheum Dis. 2016;75(12):2114-8.

6. Ramiro S, van der Heijde D, van Tubergen A, et al. Higher disease activity leads to more structural damage in the spine in ankylosing spondylitis: 12-year longitudinal data from the OASIS cohort. Ann Rheum Dis. 2014;73(8):1455-61.

7. Baraliakos X, Berenbaum F, Favalli EG, et al. Challenges and advances in targeting remission in axial spondyloarthritis. J Rheumatol. 2018;45(2):153-7.

8. van der Heijde D, Ramiro S, Landewe R, et al. 2016 update of the ASAS-EULAR management recommendations for axial spondyloarthritis. Ann Rheum Dis. 2017;76(6):978-91.

9. Schoels MM, Braun J, Dougados M, et al. Treating axial and peripheral spondyloarthritis, including psoriatic arthritis, to target: results of a systematic literature search to support an international treatto-target recommendation in spondyloarthritis. Ann Rheum Dis. 2014;73(1):238-42.

10. Braun J, Baraliakos X, Kiltz U. Secukinumab (AIN457) in the treatment of ankylosing spondylitis. Expert Opin Biol Ther. 2016;16(5):711-22. 
11. Paine A, Ritchlin CT. Targeting the interleukin-23/ 17 axis in axial spondyloarthritis. Curr Opin Rheumatol. 2016;28(4):359-67.

12. Ward MM, Deodhar A, Akl EA, et al. American College of Rheumatology/Spondylitis Association of America/Spondyloarthritis Research and Treatment Network 2015 Recommendations for the treatment of Ankylosing Spondylitis and Nonradiographic Axial Spondyloarthritis. Arthritis Care Res. 2016;68(2):151-66.

13. Baraliakos X, Haibel H, Fritz C, et al. Long-term outcome of patients with active ankylosing spondylitis with etanercept-sustained efficacy and safety after seven years. Arthritis Res Ther. 2013;15(3):R67.

14. Baraliakos X, Listing J, Fritz C, et al. Persistent clinical efficacy and safety of infliximab in ankylosing spondylitis after 8 years-early clinical response predicts long-term outcome. Rheumatology (Oxford). 2011;50(9):1690-9.

15. Braun J, van den Berg R, Baraliakos X, et al. 2010 update of the ASAS/EULAR recommendations for the management of ankylosing spondylitis. Ann Rheum Dis. 2011;70(6):896-904.

16. Baeten D, Baraliakos X, Braun J, et al. Anti-interleukin-17A monoclonal antibody secukinumab in treatment of ankylosing spondylitis: a randomised, double-blind, placebo-controlled trial. Lancet. 2013;382(9906):1705-13.

17. Baeten D, Sieper J, Braun J, et al. Secukinumab, an interleukin-17A inhibitor, ankylosing spondylitis. N Engl J Med. 2015;373(26):2534-48.

18. Baraliakos X, Kivitz AJ, Deodhar AA, et al. Longterm effects of interleukin-17A inhibition with secukinumab in active ankylosing spondylitis: 3-year efficacy and safety results from an extension of the Phase 3 MEASURE 1 trial. Clin Exp Rheumatol. 2018;36(1):50-5.

19. Marzo-Ortega H, Sieper J, Kivitz A, et al. Secukinumab provides sustained improvements in the signs and symptoms of active ankylosing spondylitis with high retention rate: 3-year results from the phase III trial, MEASURE 2. RMD Open. 2017;3(2):e000592.

20. Marzo-Ortega H, Sieper J, Kivitz A, et al. Secukinumab and sustained improvement in signs and symptoms of patients with active ankylosing spondylitis through two years: results from a phase III study. Arthritis Care Res. 2017;69(7):1020-9.

21. Braun J, Baraliakos X, Deodhar A, et al. Effect of secukinumab on clinical and radiographic outcomes in ankylosing spondylitis: 2-year results from the randomised phase III MEASURE 1 study. Ann Rheum Dis. 2017;76(6):1070-7.

22. Braun J, Baraliakos X, Deodhar A, et al. Secukinumab shows sustained efficacy and low structural progression in ankylosing spondylitis: 4-year results from the MEASURE 1 study. Rheumatology (Oxford). 2019;58(5):859-68.

23. van der Linden S, Valkenburg HA, Cats A. Evaluation of diagnostic criteria for ankylosing spondylitis. A proposal for modification of the New York criteria. Arthritis Rheum. 1984;27(4):361-8.

24. Garrett S, Jenkinson T, Kennedy LG, Whitelock H, Gaisford P, Calin A. A new approach to defining disease status in ankylosing spondylitis: the Bath Ankylosing Spondylitis Disease Activity Index. J Rheumatol. 1994;21(12):2286-91.

25. World Medical Association Declaration of Helsinki. Ethical principles for medical research involving human subjects. JAMA. 2013;310(20):2191-4.

26. Machado P, Landewe R, Lie E, et al. Ankylosing Spondylitis Disease Activity Score (ASDAS): defining cut-off values for disease activity states and improvement scores. Ann Rheum Dis. 2011;70(1): 47-53.

27. Sieper J, Rudwaleit M, Baraliakos X, et al. The Assessment of SpondyloArthritis international Society (ASAS) handbook: a guide to assess spondyloarthritis. Ann Rheum Dis. 2009;68(Suppl 2):ii1-44.

28. Haywood KL, Garratt AM, Dawes PT. Patient-assessed health in ankylosing spondylitis: a structured review. Rheumatology (Oxford). 2005;44(5): 577-86.

29. Doward L, Spoorenberg A, Cook SA, et al. Development of the ASQoL: a quality of life instrument specific to ankylosing spondylitis. Ann Rheum Dis. 2003;62(1):20-6.

30. Yellen SB, Cella DF, Webster K, Blendowski C, Kaplan E. Measuring fatigue and other anemia-related symptoms with the Functional Assessment of Cancer Therapy (FACT) measurement system. J Pain Symptom Manage. 1997;13(2):63-74.

31. Ware JE Jr. SF-36 health survey update. Spine. 2000;25(24):3130-9.

32. Loeppke R, Hymel PA, Lofland JH, et al. Healthrelated workplace productivity measurement: general and migraine-specific recommendations from the ACOEM Expert Panel. J Occup Environ Med. 2003;45(4):349-59. 
33. Machado PM, Landewe R, Heijde DV, et al. Ankylosing Spondylitis Disease Activity Score (ASDAS): 2018 update of the nomenclature for disease activity states. Ann Rheum Dis. 2018;77(10):1539-40.

34. Paccou J, Bacle-Boutry MA, Solau-Gervais E, BelePhilippe P, Flipo R-M. Dosage adjustment of antitumor necrosis factor-alpha inhibitor in ankylosing spondylitis is effective in maintaining remission in clinical practice. J Rheumatol. 2012;39(7):1418-23.

35. Anderson JJ, Baron G, van der Heijde D, Felson DT, Dougados M. Ankylosing spondylitis assessment group preliminary definition of short-term improvement in ankylosing spondylitis. Arthritis Rheum. 2001;44(8):1876-86.

36. Baraliakos X, Brandt J, Listing J, et al. Outcome of patients with active ankylosing spondylitis after two years of therapy with etanercept: clinical and magnetic resonance imaging data. Arthritis Rheum. 2005;53(6):856-63.

37. Arends S, van der Veer E, Kamps FB, et al. Patienttailored dose reduction of TNF-alpha blocking agents in ankylosing spondylitis patients with stable low disease activity in daily clinical practice. Clin Exp Rheumatol. 2015;33(2):174-80.

38. Braun J, Brandt J, Listing J, et al. Treatment of active ankylosing spondylitis with infliximab: a randomised controlled multicentre trial. Lancet. 2002;359(9313):1187-93.

39. Davis JC Jr, Van Der Heijde D, Braun J, et al. Recombinant human tumor necrosis factor receptor (etanercept) for treating ankylosing spondylitis: a randomized, controlled trial. Arthritis Rheum. 2003;48(11):3230-6.

40. Inman RD, Davis JC Jr, Heijde D, et al. Efficacy and safety of golimumab in patients with ankylosing spondylitis: results of a randomized, double-blind, placebo-controlled, phase III trial. Arthritis Rheum. 2008;58(11):3402-12.

41. van der Heijde D, Dijkmans B, Geusens P, et al. Efficacy and safety of infliximab in patients with ankylosing spondylitis: results of a randomized, placebo-controlled trial (ASSERT). Arthritis Rheum. 2005;52(2):582-91.

42. van der Heijde D, Kivitz A, Schiff MH, et al. Efficacy and safety of adalimumab in patients with ankylosing spondylitis: results of a multicenter, randomized, double-blind, placebo-controlled trial. Arthritis Rheum. 2006;54(7):2136-46.

43. van der Heijde D, Deodhar A, Braun J, et al. The effect of golimumab therapy on disease activity and health-related quality of life in patients with ankylosing spondylitis: 2-year results of the GO-RAISE trial. J Rheumatol. 2014;41(6):1095-103.

44. Landewe R, Braun J, Deodhar A, et al. Efficacy of certolizumab pegol on signs and symptoms of axial spondyloarthritis including ankylosing spondylitis: 24-week results of a double-blind randomised placebo-controlled Phase 3 study. Ann Rheum Dis. 2014;73(1):39-47.

45. Braun J, Baraliakos X, Brandt J, et al. Persistent clinical response to the anti-TNF-alpha antibody infliximab in patients with ankylosing spondylitis over 3 years. Rheumatology (Oxford). 2005;44(5): 670-6.

46. Deodhar AA, Dougados M, Baeten DL, et al. Effect of secukinumab on patient-reported outcomes in patients with active ankylosing spondylitis: a phase III randomized trial (MEASURE 1). Arthritis Rheumatol. 2016;68(12):2901-10. 